\title{
Translation of an evidence-based asthma intervention: Physician Asthma Care Education (PACE) in the United States and Australia
}

\section{Minal R Patel', Smita Shah'2, Michael D Cabana ${ }^{3}$, Susan M Sawyer ${ }^{4}$, Brett Toelle ${ }^{5}$, Craig Mellis², Christine Jenkins², Randall W Brown', *Noreen M Clark'}

\author{
${ }^{1}$ Center for Managing Chronic Disease, University of Michigan, Ann Arbor, MI, USA \\ 2 University of Sydney, NSW, Australia \\ ${ }^{3}$ Division of General Pediatrics, University of California San Francisco, San Francisco, CA, USA \\ ${ }^{4}$ Centre for Adolescent Health, Royal Children's Hospital; Department of Pediatrics, The University of Melbourne; Murdoch Children's \\ Research Institute, Melbourne, VIC, Australia \\ ${ }^{5}$ Woolcock Institute of Medical Research, NSW, Australia
}

Originally received 19th June 2012; resubmitted 28th August 2012; revised 26th September 2012; accepted 27th September 2012; online 8th November 2012

\begin{abstract}
Background: Physician Asthma Care Education (PACE) is a programme developed in the USA to improve paediatric asthma outcomes. Aims: To examine translation of PACE to Australia.

Methods: The RE-AIM framework was used to assess translation. Demographic characteristics and findings regarding clinical asthma outcomes from PACE randomised clinical trials in both countries were examined. Qualitative content analysis was used to examine fidelity to intervention components.

Results: Both iterations of PACE reached similar target audiences (general practice physicians and paediatric patients with asthma); however, in the USA, more children with persistent disease were enrolled. In both countries, participation comprised approximately $10 \%$ of eligible physicians and $25 \%$ of patients. In both countries, PACE deployed well-known local physicians and behavioural scientists as facilitators. Sponsorship of the programme was provided by professional associations and government agencies. Fidelity to essential programme elements was observed, but PACE Australia workshops included additional components. Similar outcomes included improvements in clinician confidence in developing short-term and long-term care plans, prescribing inhaled corticosteroids, and providing written management instructions to patients. No additional time was spent in the patient visit compared with controls. US PACE realised reductions in symptoms and healthcare use, results that could not be confirmed in Australia because of limitations in follow-up time and sample sizes. US PACE is maintained through a National Heart, Lung, and Blood Institute website. Development of maintenance strategies for PACE Australia is underway.

Conclusions: Based on criteria of the RE-AIM framework, the US version of PACE has been successfully translated for use in Australia. (C) 2013 Primary Care Respiratory Society UK. All rights reserved.

MR Patel et al. Prim Care Respir J 2013; 22(1): 29-34

http://dx.doi.org/10.4104/pcrj.2012.00093
\end{abstract}

Keywords asthma, children, interventions, primary care, translation

See linked editorial by Tomlins on pg 6

\section{Introduction}

The prevalence of asthma in both the USA and Australia is among the highest in the world, ${ }^{1}$ with $10 \%$ (2 million) of Australians and
$8.2 \%$ (24.6 million) of the US population reporting a physician's diagnosis. 2,3 In each country, urgent healthcare use and school absenteeism for children attributable to asthma are well above national averages. ${ }^{2,3}$

Physician Asthma Care Education (PACE) is an interactive

\footnotetext{
*Corresponding author: Dr Noreen M Clark, Center for Managing Chronic Disease, University of Michigan, 1415 Washington Heights, Ann Arbor, MI 48109-2029, USA. Tel: +1 (734) 763-1457 Fax: +1 (734) 763-9115 E-mail: nmclark@umich.edu
} 


\section{Box 1. Overview of PACE}

Guided by social cognitive theory and principles of self-regulation, PACE is an interactive seminar that provides education for clinicians on how to employ the best clinical therapies for asthma, how to communicate more effectively with patients, and support patients' management efforts. Several activities and materials are used in the seminar to convey concepts and enable acquisition of skills, including brief lectures on clinical practice from respected asthma specialists; a video depicting effective clinician teaching and communications behaviour; case studies presenting troublesome clinical problems; a protocol by which physicians can assess their own behaviour regarding patient communications; and review of messages to communicate and materials to use when teaching patients. ${ }^{4}$ The seminar comprises two face-to-face group meetings lasting $2.5 \mathrm{hrs}$ each, held over a two-week period.

seminar developed in the USA for general practice physicians (Box 1). Delivered by a team including an asthma specialist, a general practice paediatrician and a behavioural scientist, PACE provides concepts and skills for primary care clinicians on how to use the best clinical therapies for asthma, communicate more effectively with patients, and support patients' management efforts (Table 1). ${ }^{4}$ In the
USA, efficacy and effectiveness trials of PACE illustrated improved physician practices, patient perceptions of physician behaviour, children's symptoms, and urgent healthcare use. ${ }^{4,5}$ Physicians who received the PACE intervention spent the same amount of time in clinical encounters with patients as non-PACE physicians.

In Australia, a trial of PACE was conducted after adaptation of the programme to the Australian health system. ${ }^{6,7}$ Significant outcomes included more children receiving written asthma action plans and prescribed medications more closely aligned with children's clinical pattern of asthma.

The research presented here examined the translation of PACE from the USA to Australia by comparing characteristics of the study population, similarities and differences in intervention components, patient/provider outcomes, and maintenance efforts.

\section{Methods}

The Reach, Effectiveness, Adoption, Implementation, and Maintenance (RE-AIM) framework is an approach developed in the USA to assess the public health impact of an intervention (Box 2). ${ }^{8}$ The dimensions of RE-AIM, as used in this study, are presented in Table 2.8,9

Data from the randomised controlled trials of effectiveness of

Table 1. Comparison of essential programme elements of the PACE programme in the USA and Australia

\begin{tabular}{|c|c|c|}
\hline \multirow[t]{2}{*}{ Similar components } & \multicolumn{2}{|l|}{ Different components } \\
\hline & USA & Australia \\
\hline \multicolumn{3}{|l|}{ Clinical aspects of asthma and long-term management } \\
\hline $\begin{array}{ll}\text { - } & \text { Trends of asthma in primary care practice } \\
\text { - } & \text { Components of good asthma control } \\
\text { - } & \text { Written instructions and asthma action plans } \\
\text { - } & \text { Review of the long-term treatment plan } \\
\text { - } & \text { Asthma medications } \\
\text { - Cases of asthma diagnosis }\end{array}$ & & $\begin{array}{l}\text { - Focus on patterns of asthma } \\
\text { - Straw activity: rehearsal of a patient } \\
\text { teaching technique (breathing through } \\
\text { a pinched straw) }\end{array}$ \\
\hline \multicolumn{3}{|l|}{ Communication strategies } \\
\hline $\begin{array}{ll}\text { - } & \text { Theoretical background (Health Belief Model) } \\
\text { - } & \text { Evidence on asthma medication adherence } \\
\text { - } & \text { Evidence from efficacy trial of US PACE } \\
\text { - } & \text { discussion demonstration: communication strategies + } \\
\text { - } \quad \text { Using the self-rating scale and using } \\
\text { communicating strategies with patients between } \\
\text { intervention sessions + reflection with group }\end{array}$ & $\begin{array}{l}\text { - Barriers to effective } \\
\text { communication }\end{array}$ & $\begin{array}{l}\text { - Note: video remade for the } \\
\text { Australian setting }\end{array}$ \\
\hline \multicolumn{3}{|l|}{ Patient education messages } \\
\hline - Video of patient education message + discussion & & $\begin{array}{l}\text { - Note: video remade for the } \\
\text { Australian setting }\end{array}$ \\
\hline \multicolumn{3}{|l|}{ Cases } \\
\hline - $\quad$ Asthma treatment cases + discussion & & - Activity: writing an asthma action plan \\
\hline \multicolumn{3}{|l|}{ Remuneration } \\
\hline - $\quad$ Billing and coding for asthma education & $\begin{array}{l}\text { - } \quad \text { Specific to CPT and ICD-9 } \\
\text { codes for asthma }\end{array}$ & $\begin{array}{l}\text { - Presentation of the Asthma Cycle } \\
\text { of Care }\end{array}$ \\
\hline \multicolumn{3}{|l|}{ Additional components } \\
\hline & & $\begin{array}{l}\text { - Teaching the use of asthma devices } \\
\text { - Quiz show: content mastery }\end{array}$ \\
\hline
\end{tabular}




\section{Box 2. Overview of RE-AIM}

RE-AIM provides a framework for identifying programmes that work in real-world environments. It is conceptualised as the public health impact of an intervention as a function of five factors: Reach, Effectiveness, Adoption, Implementation, and Maintenance. A central tenet is that the ultimate impact of an intervention is due to its combined effects on five evaluative dimensions. The model can be used to guide qualitative evaluation efforts by focusing inquiry on each of these issues. To the extent that RE-AIM dimensions are incorporated into evaluations, decision makers will have more complete information on which to base adoption or discontinuance of programmes.

PACE in the USA and Australia were used to populate dimensions of RE-AIM. Study methods for the PACE trials are described elsewhere. ${ }^{4,5,7}$ The US trial was conducted between 2001 and 2004 and the Australia trial was conducted between 2006 and 2009. Study procedures for both the US and Australian trials received prior ethical approval from sponsoring institutions. ${ }^{5,7}$ In both the US and Australia, participating clinicians provided informed consent for their participation and, before telephone contact, the participating paediatricians sent a letter that explained the study to each household of potential study participants. Parents of patients could contact the physician's office to have their names removed from the list of potential participants. In the US trial, 101 primary care physicians were surveyed and 870 parents of their paediatric patients with asthma completed baseline interviews; 731 patients provided follow-up data detailing clinical information, perceptions of care provided, and performance of their physician. In the Australian trial, a total of 122 general practitioners and 221 patients completed baseline interviews and 213 patients completed followup interviews based on the same items posed to US participants. Data collection methods in both countries included telephone interviews and, in the US, verification through medical records. In the US the follow-up period was 24 months and in Australia it was 12 months. Similar analytical techniques were employed within both countries' trials to examine sample characteristics and evaluate the impact of the PACE intervention on outcomes: symptoms, healthcare use, and clinical practices. Descriptive statistics (means and standard deviations, and frequencies) and multivariate regression (specifically linear, logistic, and Poisson regression) adjusting for appropriate confounders were employed. . $5,7^{5}$

Similarities and differences in implementation of the intervention together with maintenance efforts were assessed through a qualitative content analysis of PACE programme protocols as applied in the US and Australia and related programme documents. A list of essential intervention components developed in the efficacy trial of PACE was generated in the form of codes. ${ }^{4}$ Facilitator intervention manuals for both the US and Australia were matched by code for intervention components to ascertain similarities and differences in essential elements. Quantitative evaluation results and qualitative content analyses were then assigned to criteria of the RE-AIM framework (see Table 2).

In Australia the PACE acronym was changed to Practitioner Asthma Communication and Education to reflect the fact that a core aspect of the programme was the importance of communication.

\section{Results}

\section{Reach}

The reach dimension in the RE-AIM framework examines the representativeness and proportion of individuals who are willing to participate in a given intervention ${ }^{8}$ - in this case, the extent to which target physicians participated in PACE and the extent to which they served targeted patient groups. Criteria for participating physicians in both the US and Australia included being a primary care provider to children with asthma. In the Australian study children with asthma aged 2-14 years were included while, in the US, children with asthma aged 2-12 years were included in the study. The inclusion criteria also included the absence of any other disease with pulmonary complications and at least one hospitalisation, emergency department (ED) visit, or urgent office visit for asthma within the previous 2 years.

In the US, PACE was evaluated in 10 cities. A total of 101 paediatricians from a list of 1,219 general practitioners who fully met the criteria for participation agreed to participate and provided

Table 2. RE-AIM evaluation dimensions

RE-AIM dimension

Reach: proportion of the target population that participated in the intervention and representativeness of individuals included

Effectiveness: success rate in terms of outcomes

Adoption: representativeness of settings and intervention agents who are willing to

initiate a programme

Implementation: extent to which intervention is implemented as intended in the real-world; adaptation to local circumstances

Maintenance: long-term follow-up of individuals and extent to which the programme

is sustained over time

Adapted from references 8, 9, 23.
Social ecological level of impact

Individual

Individual

Organisational

Organisational

Individual and organisational 


\begin{tabular}{|c|c|c|}
\hline Factor & USA $(n=94)$ & Australia $(n=122)$ \\
\hline Male & $53 \%(n=50)$ & $39 \%(n=47)$ \\
\hline $\begin{array}{l}\text { Mean (SD) years since medical } \\
\text { school graduation }\end{array}$ & $17.95(9.4)$ & $18.59(10.24)$ \\
\hline $\begin{array}{l}\text { Mean (SD) number of asthma } \\
\text { patients in practice }\end{array}$ & $170(168)$ & $12.34(15.49)^{*}$ \\
\hline Advanced licence in general practice & $78 \%(n=73)$ & $62 \%(n=76)$ \\
\hline \multicolumn{3}{|l|}{ Practice setting } \\
\hline Solo physician & $12 \%(n=11)$ & $13 \%(n=16)$ \\
\hline Group practice & $79 \%(n=74)$ & $80 \%(n=97)$ \\
\hline Other & $9 \%(n=9)$ & $0 \%(n=0)$ \\
\hline
\end{tabular}

consent; 94 physicians provided baseline data. A list of 3,368 of their patients was generated, of which 2,300 who met the inclusion criteria were randomly selected for participation. Of these, 870 families consented to participate. In Australia, 2,209 general practitioners comprised lists in two regions in Sydney, 150 met the inclusion criteria and expressed interest and, of these, 122 consented to participate. A list of 1,290 of their patients was generated, of whom 235 met the eligibility criteria and 221 agreed to participate. In both the US and Australia, the proportion of the population willing to participate in PACE was approximately $5-8 \%$ of general practitioners and $17-25 \%$ of their paediatric asthma patients. The major reason for non-participation of physicians in both countries was time constraints, but a number of US physicians declined because they believed they were already compliant with guideline-recommended asthma care. ${ }^{10}$ Although self-reported rates of adherence to asthma guidelines are low (between 39\% and $53 \%$ ), some barriers that physicians face in implementing guidelinerecommended care include inertia of previous practice (i.e. inability to change practice patterns). ${ }^{11,12}$

Tables 3 and 4 show the characteristics of clinicians and patients who participated in PACE in the US and Australia. Table 3 shows that, in both countries, the majority of physicians were licensed as general practitioners, worked in a group practice setting, and had an average length of time in practice of nearly two decades. More male than female physicians participated in PACE in the US while the reverse was the case in Australia.

Table 4 shows that both US and Australian parents and patients whose physicians participated in PACE were similar in terms of educational attainment, household income, and level of children's baseline urgent care use for asthma. The mean age of children reached was similar. Three times as many US patients had symptoms consistent with persistent asthma. The percentage or parents who smoked was the same in both countries.

\section{Effectiveness}

The effectiveness dimension in the RE-AIM framework examines the impact of an intervention on important outcomes. ${ }^{8}$ Table 5 shows outcomes assessed in both the US and Australia related to physicians' confidence in delivering aspects of asthma care, parent
Table 4. Patient characteristics in PACE trials in both the USA and Australia

\begin{tabular}{|c|c|c|}
\hline Factor & USA $(n=870)$ & Australia $(n=221)$ \\
\hline Male & $64 \%(n=554)$ & $68 \%(n=151)$ \\
\hline Mean (SD) age of child (years) & $7.0(2.9)$ & 6.9 (3.3) \\
\hline Persistent asthma & $37 \%(n=325)$ & $10 \%(n=21)$ \\
\hline \multicolumn{3}{|l|}{ Relationship to child } \\
\hline Mother & $93 \%(n=813)$ & $92 \%(n=203)$ \\
\hline Father & $4 \%(n=35)$ & $12 \%(n=26)$ \\
\hline Other & $2 \%(n=18)$ & $3 \%(n=6)$ \\
\hline Person in household who smokes & $13 \%(n=112)$ & $17 \%(n=38)$ \\
\hline $\begin{array}{l}\text { Household total income less than } \\
\text { AUD } 60,000 / \text { year }\end{array}$ & $50 \%(n=432)^{*}$ & $30 \%(n=67)$ \\
\hline \multicolumn{3}{|l|}{ Parent education } \\
\hline Did not complete high school & $3 \%(n=29)$ & $0 \%(n=0)$ \\
\hline $\begin{array}{l}\text { Completed high school but } \\
\text { not college }\end{array}$ & $60 \%(n=528)$ & $51 \%(n=112)$ \\
\hline Completed college or more & $38 \%(n=336)$ & $48 \%(n=106)$ \\
\hline \multicolumn{3}{|l|}{ Baseline healthcare utilisation } \\
\hline $\begin{array}{l}\text { Hospital admissions per year, } \\
\text { mean (SD) }\end{array}$ & $0.13(0.50)$ & $0.42(0.70)$ \\
\hline $\begin{array}{l}\text { Emergency department asthma } \\
\text { visits per year, mean (SD) }\end{array}$ & $0.75(1.9)$ & $1.55(0.57)$ \\
\hline $\begin{array}{l}\text { Emergency doctor office visits } \\
\text { per year, mean (SD) }\end{array}$ & $1.75(2.9)$ & $2.05(1.1)$ \\
\hline
\end{tabular}

perception of the clinician's care, and child health outcomes. In both countries the PACE intervention improved the clinician's confidence to develop short-term and long-term asthma care plans and to review them with their patients. In Australia, general practitioners also reported increased confidence in using the Asthma Cycle of Care, the national programme that provides reimbursement for routine follow-up for asthma patients. General practitioners in both countries reported no differences in time spent with patients for both newly diagnosed and previously diagnosed patients.,

Patients in Australia were more likely to have been given an asthma action plan and, in the US, comparable written instructions on how to use medicines at home. Prescriptions for inhaled corticosteroids (ICS) improved in both countries. In Australia, fewer patients with intermittent disease were given ICS whereas, in the US, more newly diagnosed patients were treated with ICS including combination drugs (e.g. Advair). Parents in the US rated physicians' performance higher on several behaviours: finding out the family's biggest asthma concern; informing the parent that the child could be fully active; and asking the parent if the child has met specific goals of therapy.

Given the patient sample size and duration of the study in the US, it was possible to assess healthcare utilisation at 12 and 24 months post-intervention. There were significant reductions at 12 months in the number of days of activity limitation attributable to 
Table 5. Comparison of PACE intervention outcomes between the USA and Australia

\begin{tabular}{|c|c|c|c|c|}
\hline & \multicolumn{2}{|l|}{ USA } & \multicolumn{2}{|l|}{ Australia } \\
\hline & Estimate* & $\mathrm{p}$ Value & Estimate $^{\dagger}$ & $\mathrm{p}$ Value \\
\hline \multicolumn{5}{|l|}{ GP outcomes } \\
\hline $\begin{array}{l}\text { GP confidence in their ability to develop a short-term plan for asthma } \\
\text { (adjusted odds ratio) }\end{array}$ & 3.79 & $<0.05$ & 1.60 & 0.02 \\
\hline $\begin{array}{l}\text { GP confidence in their ability to review the long-term plan for care with } \\
\text { patients (adjusted odds ratio) }\end{array}$ & 3.72 & $<0.05$ & 1.27 & 0.02 \\
\hline $\begin{array}{l}\text { Increased use of Asthma Cycle of Care }{ }^{* *} \text { (\% difference between control } \\
\text { and intervention groups) }\end{array}$ & & & $29.9 \%$ & 0.004 \\
\hline \multicolumn{5}{|l|}{ Parent report of provider behaviour } \\
\hline $\begin{array}{l}\text { GP informed the parent that the child could be fully active (\% difference } \\
\text { between control and intervention groups) }\end{array}$ & $12.0 \%$ & 0.01 & $-6.9 \%$ & 0.27 \\
\hline GP asked parent if met specific goals with therapy (adjusted odds ratio) & 1.50 & $<0.05$ & 2.28 & 0.37 \\
\hline $\begin{array}{l}\text { GP provided written instructions for adjusting medicines (\% difference } \\
\text { between control and intervention groups) }\end{array}$ & $10.0 \%$ & 0.03 & $18.4 \%$ & 0.01 \\
\hline $\begin{array}{l}\text { GP provided prescription of ICS (\% difference between control and } \\
\text { intervention groups) }\end{array}$ & $12.4 \%$ & 0.02 & $-24.0 \%$ & 0.03 \\
\hline GP finds out the parent's biggest asthma concern $\neq \neq$ & $0.20 \S$ & 0.01 & $-1.9 \%$ & 0.68 \\
\hline \multicolumn{5}{|l|}{ Child patient asthma outcomes } \\
\hline Number of days of activity limitation (mean difference) $)^{\ddagger \ddagger}$ & $-7.1 \neq \S$ & $<0.05$ & $4.9 \% \neq \emptyset$ & 0.25 \\
\hline Emergency department utilisation for asthma $a_{\ddagger \neq}$ & $-0.55^{\ddagger \S}$ & $<0.05$ & $6 \% 9$ & 0.12 \\
\hline \multicolumn{5}{|c|}{$\begin{array}{l}\text { *Estimates from references } 4 \text { and } 5 .{ }^{\dagger} \text { Estimates from reference } 7 .{ }^{\ddagger} \text { Negative difference favours intervention group. } \$ \text { Difference in mean scores between } \\
\text { intervention and control group } 9 \text { Percentage difference between control and intervention groups assessed on an ordinal response scale **Programme unique tc } \\
\text { the Australian health system. }{ }^{+\dagger} \text { Australia: less prescription to children with intermittent asthma; USA: newly diagnosed children treated. }{ }^{\ddagger \neq} \text { Different response } \\
\text { scales used in each country. However, direction and significance of change was the same in both countries. }\end{array}$} \\
\hline
\end{tabular}

asthma and the number of ED visits. Two-year follow-up evaluation in the US showed that children whose physicians participated in PACE had significant reductions compared with controls in symptoms and urgent care use - specifically, fewer sleep disruptions from asthma symptoms; fewer ED visits, hospitalisations, and urgent office visits; and fewer telephone calls to the doctor's office. ${ }^{13}$ Because of the shorter study duration and smaller sample size, it was not possible to assess these effects in Australia. However, it is reasonable to assume that, given the similarity of other key outcomes, Australia PACE could be expected to realise comparative results regarding healthcare use since asthma-related urgent care use in both the US and Australia stem from deficiencies in patient education. 2,14

\section{Adoption}

Adoption in the RE-AIM framework is to assess similarities in communities in terms of resources and intervention agents (people who deliver the programme) who are willing to initiate a programme. $^{8}$ Because the social cognitive theoretical basis of PACE considers the use of credible role models central to change, appropriate intervention deliverers are deemed critical to its effectiveness. The intervention in both the US and Australia deployed well-known local general practice physician leaders, asthma specialists, and behavioural scientists as facilitators at intervention sites. Leaders were chosen based on their background, reputation in the community, and engagement with an organisation that provides continuing medical education (CME) credit to physicians. Each PACE team was trained by the programme coordinators to deliver the intervention according to a standardised protocol.

In both countries, local general practitioner professional societies provided support with recruitment of physicians for the intervention. Programme coordination in Australia was provided by the University of Sydney in collaboration with the Woolcock Institute of Medical Research and the Center for Adolescent Health, Royal Children's Hospital in Melbourne. The Center for Managing Chronic Disease at the University of Michigan coordinated the programme in the US. In both countries, funding for the evaluation of PACE was provided by government agencies and foundations. Specifically, in Australia the trial was funded by the Australian Government Department of Health and Aging, Chronic Disease Programs and, in the US, funding was provided by the Robert Wood Johnson Foundation and the National, Heart, Lung, and Blood Institute (NHLBI).

\section{Implementation}

Implementation in the RE-AIM framework refers to fidelity to key components of an intervention protocol and consistent delivery. ${ }^{8} \mathrm{~A}$ comparison of essential programme elements for the PACE programme in the US and Australia is shown in Table 1. Essential components of PACE include guideline-recommended clinical practices, 10 communication strategies, 10 specific patient asthma education messages, clinical case studies, and remuneration options. 
Based on a feasibility study of PACE in Australia with 25 general practitioners, it was adapted to the Australian setting with additional activities, and asthma care content was changed to reflect Australia's clinical guidelines for the diagnosis and management of asthma. ${ }^{6}$ In Australia the workshops were extended by an hour and included activities such as practice in writing action plans, a brief quiz show to demonstrate content mastery, and asthma device demonstrations and practice. Each participant received a set of placebo asthma inhalers, spacers, peak flow meters, and model airways.

Because of differences between the two countries in how healthcare is financed, the original remuneration content was reshaped for the Australian programme. In the US the remuneration content included a review of CPT and ICD-9 codes for asthma consultations and education. In Australia, the remuneration content included a review of the Asthma Cycle of Care plan, which is a national programme in Australia that gives providers incentives in the form of reimbursement for implementing guidelinerecommended care for asthma patients. ${ }^{15}$ One of the objectives of PACE Australia was to help general practitioners achieve the goals of the Asthma Cycle of Care. ${ }^{15}$

The delivery cost of PACE in the US ranged from $\$ 2,500$ to $\$ 5,500$, which included honoraria for facilitators, dinner for physician participants, equipment rental, CME fees, and participant kits and handouts. ${ }^{10}$ In Australia, similar expenses totaled about $\$ 2,000$ Australian dollars.?

\section{Maintenance}

Maintenance in RE-AIM refers to long-term follow-up to assess outcomes for participants in the intervention and the extent to which a programme becomes an ongoing part of routine organisational practices and policies. ${ }^{8}$ As noted previously, two-year follow-up evaluation in the US demonstrated that patients of physicians who participated in PACE had a significant reduction in symptoms and urgent care use compared with controls. Due to funding limitations, Australia was not able to assess long-term outcomes of PACE such as healthcare utilisation; however, as noted, similar benefits could arguably be expected with additional followup, given the findings of the US evaluation.

In the US there is evidence of maintenance of the programme as a result of continued access to the intervention for physicians and expansion to new locales. US PACE is freely available through the National Heart, Lung, and Blood Institute website..$^{16}$ The National Asthma Control Initiative, a National Institutes of Health effort to support implementation of asthma guidelines, has also made PACE information and training available. ${ }^{17}$ PACE has been offered in communities across the US. Maintenance strategies for PACE Australia are being actively explored nationwide through the National Asthma Council of Australia and government agencies.

\section{Discussion}

\section{Main findings}

Translation of PACE in Australia produced similar improvements in clinicians' practice observed in the US - specifically, providing prescriptions for ICS and written asthma management plans and instructions to patients. In addition to these outcomes, US PACE also generated significant reductions in symptoms and healthcare use. Essential characteristics of participating physicians and patients were similar in both countries. Programme fidelity was observed and delivery procedures the same. Careful pilot work contributed to translation.

\section{Interpretation of findings in relation to previously published work}

PACE achieved important asthma outcomes in two countries where guideline-recommended practices for asthma are much less evident among general practitioners than asthma specialists. The need for building general practitioner capacity has been discussed in the literature of both countries. ${ }^{18,19}$

Nearly all efforts to provide CME face challenges. Competing practice demands of physicians are great as practitioners must respond to heavy clinical service expectations and have many CME opportunities from a variety of conventional sources..$^{10}$ Attracting physicians to CME is a challenge. Methods of recruitment for the PACE studies that included face-to-face contact with clinicians from a medical peer was found to be essential in gaining clinician interest in a programme with somewhat high participation expectations.

PACE programme coordination efforts by institutions with a track record for asthma-related outreach in local communities proved useful for obtaining practitioner buy-in and comprised an important CME recruitment strategy, as did efforts to appeal to clinician priorities. For example, to address the perception of poor remuneration for patient education, in the US the reimbursement module illustrated how to make optimum documentation, coding, and billing. ${ }^{20}$ An additional attractive feature of PACE in both countries was the lack of conflict of financial interest, often evident when pharmaceutical companies sponsor CME activities. ${ }^{10}$

The proportion of eligible practitioners - and therefore their patients - willing to participate in the intervention was low in both the US and Australia. The added burden of randomised controlled trial evaluation probably contributed to the lower rate. These challenges are common in primary care trials..$^{21}$ Added evaluation burdens probably reduced attractiveness to busy clinicians. When these extra requirements are not needed, participation levels are higher..22

\section{Strengths and limitations of this study}

RE-AIM has been used to plan, evaluate, and review a variety of health promotion and disease management interventions and has appeared in over 150 published studies. ${ }^{23}$ As an assessment tool, REAlM proved useful in framing the important dimensions of assessment and those most important for ensuring reach, impact, and sustainability. In Australia, PACE used an abbreviated outcome assessment tool at each time point as there were concerns about the burden for physicians and patients if the original longer US versions were used. However, key evaluation questions were preserved to ensure that important comparisons could be made.

Australia and the US have similarities including a dominant language, political structures, and medical practice. The study did not examine translation to a venue with dramatically different features from those in the US. Coordinating entities in both countries were academic institutions. Translation by other types of organisations was not tested. 
Implications for future research, policy, and practice Translation of evidence-based programmes in chronic disease management has been widely described as a priority of healthcare delivery. ${ }^{24-26}$ The US National Institutes of Health Roadmap for Medical Research recently expanded research translation steps to encourage practice-based research (T3) that improves incorporation of research discoveries into day-to-day clinical care. ${ }^{27}$ This study contributed to understanding dimensions of translation of physician education from one locale to another. Based on the RE-AIM framework for assessing translation and dissemination of interventions, US PACE has been successfully translated for use in Australia. To our knowledge, the analysis presented here is the first to use the RE-AIM framework to assess the translation of a childhood asthma intervention between countries with varying economic, political, and health system structures. Given that both the US and Australia face similar challenges with managing asthma, PACE may be most effective in regions where asthma morbidity stems from deficiencies in guidelinerecommended care and patient education associated with asthma.

Several translation lessons were learned. Given the extent of the modifications of PACE needed for the Australian healthcare setting, ${ }^{6}$ an important aspect of adaptation is for intervention activities to be piloted and appropriately tailored to the new target population while, at the same time, assuring fidelity to the key elements of the original programme. For example, in the Australian programme the term 'physician' was changed to 'practitioner' to recognise the range of clinicians seeing asthma patients. PACE has been adapted for nurses in the clinical setting by Education for Health in the UK and a version is available to nurses online through their website. ${ }^{28}$ It is likely that further adaptations for asthma educators and respiratory therapists could contribute to improved outcomes for children with asthma. Elements needed in such pilot processes to ensure effective adoption deserves study in future research. Given the extent of evaluation of PACE through rigorous designs, simple evaluations could be employed in translating PACE to other regions - for example, training all members of a group practice together and collecting only postprogramme process information. Lastly, translation of PACE relied heavily on successful partnerships with local physicians. Thus, it is also important that programme coordination and intervention delivery achieve active engagement of influential members of the target population in the community undertaking translation.

\section{Conclusion}

Translation of the evidence-based US PACE programme to Australia achieved successful deployment of key intervention components, reach to a similar clinician and patient audience, and similar outcomes including appropriate provision of ICS, written asthma management plans, and instructions to patients. US PACE achieved significant improvements in symptoms and reduced healthcare use in patients, and the results are expected to be comparable in Australia in a larger sample of patients. Based on the criteria of the RE-AIM framework, the US version of PACE has been successfully translated for use in Australia.

\section{Handling editor Hilary Pinnock \\ Statistical review Gopal Netuveli}

Acknowledgements The authors would like to thank Katherine Faiver (University of Michigan) and Pin-Pin Song (University of Michigan) for their assistance with formatting this manuscript, and Edward Green (University of Michigan) for statistical assistance.

Conflicts of interest SS and RWB have received research support from Astra Zeneca Pharmaceuticals. MDC and RWB have been advisors and members of the Merck Pharmaceuticals speaker's bureau. MRP, SS, CJ, BT, CM, and NMC have no conflicts of interest in relation to this article.

Contributorship MRP and SS contributed to study concept and design, analysis and interpretation of the data, and drafting and revision of the manuscript. $M D C, S S, C M, B T, C J$, and RWB contributed to drafting and revision of the manuscript. NMC contributed to study concept and design, interpretation of the data, and drafting and revision of the manuscript.

Funding In Australia this work was supported by the Australian Government Department of Health and Aging, Asthma Management Program and, in the USA, by the National, Heart, Lung, and Blood Institute and the Robert Wood Johnson Foundation (Princeton, NJ).

\section{References}

1. Masoli M, Fabian D, Holt S, Beasley R. Global Initiative for Asthma (GINA): Global Burden of Asthma. 2012. Available from: http://www.ginasthma.org/reports-globalburden-of-asthma.html (cited 18 Apr 2012).

2. Australian Centre for Asthma Monitoring. Asthma in Australia 2011: with a focus chapter on chronic obstructive pulmonary disease. Asthma series no. 4. Cat. no. ACM 22. Canberra: AlHW. 2011. Available from: http://www.aihw.gov.au/ publication-detail/?id=10737420159 (cited 2 Mar 2012).

3. Centers for Disease Control and Prevention (CDC). Vital signs: asthma prevalence, disease characteristics, and self-management education: United States, 2001-2009. MMWR Morb Mortal Wkly Rep 2011;60(17):547-52.

4. Clark NM, Gong M, Schork MA, et al. Impact of education for physicians on patient outcomes. Pediatrics 1998;101(5):831-6. http://dx.doi.org/10.1542/peds.101.5.831

5. Cabana MD, Slish KK, Evans D, et al. Impact of physician asthma care education on patient outcomes. Pediatrics 2006;117(6):2149-57. http://dx.doi.org/10.1542/ peds.2005-1055

6. Shah S, Toelle BG, Sawyer SM, et al. Feasibility study of a communication and education asthma intervention for general practitioners in Australia. Aust J Prim Health 2010;16(1):75-80. http://dx.doi.org/10.1071/PY09056

7. Shah S, Sawyer SM, Toelle BG, et al. Improving paediatric asthma outcomes in primary health care: a randomised controlled trial. Med J Aust 2011;195(7):405-09. http://dx.doi.org/10.5694/mja10.11422

8. Glasgow RE, Vogt TM, Boles SM. Evaluating the public health impact of health promotion interventions: the RE-AIM framework. Am J Public Health 1999;89(9):1322-7. http://dx.doi.org/10.2105/AJPH.89.9.1322

9. Glasgow RE, McKay HG, Piette JD, Reynolds KD. The RE-AIM framework for evaluating interventions: what can it tell us about approaches to chronic illness management? Patient Educ Couns 2001;44(2):119-27. http://dx.doi.org/10.1016/ S0738-3991(00)00186-5

10. Cabana MD, Brown $\mathrm{R}$, Clark NM, et al. Improving physician attendance at educational seminars sponsored by managed care organizations. Manag Care 2004;13(9):49-51.

11. Cabana MD, Rand CS, Becher OJ, Rubin HR. Reasons for pediatrician nonadherence to asthma guidelines. Arch Pediatr Adolesc Med 2001;155(9):1057-62.

12. Cabana MD, Rand CS, Powe NR, et al. Why don't physicians follow clinical practice guidelines? A framework for improvement. JAMA 1999;282(15):1458-65.

13. Clark NM, Cabana M, Kaciroti N, Gong M, Sleeman K. Long-term outcomes of physician peer teaching. Clin Pediatr (Phila) 2008;47(9):883-90.

14. Flores G, Abreu M, Tomany-Korman S, Meurer J. Keeping children with asthma out of hospitals: parents' and physicians' perspectives on how pediatric asthma hospitalizations can be prevented. Pediatrics 2005;116(4):957-65.

15. National Asthma Council of Australia. Asthma Cycle of Care. 2012. Available from: http://www.nationalasthma.org.au/publication/asthma-cycle-of-care (cited 18 Apr 2012)

16. National Heart, Lung, and Blood Institute. Physician Asthma Care Education. 2006. Available from: http://www.nhlbi.nih.gov/health/prof/lung/asthma/pace/index.htm (cited 18 Apr 2012)

17. National Heart, Lung, and Blood Institute. Asthma, National Asthma Control 
Initiative. 2011. Available from: http://www.nhlbi.nih.gov/health/prof/lung/ asthma/naci/ (cited 18 Apr 2012).

18. Finkelstein JA, Lozano $P$, Shulruff $R$, et al. Self-reported physician practices for children with asthma: are national guidelines followed? Pediatrics 2000;106(4):88696.

19. Wisnivesky JP, Lorenzo J, Lyn-Cook R, et al. Barriers to adherence to asthma management guidelines among inner-city primary care providers. Ann Allergy Asthma Immunol 2008;101(3):264-70. http://dx.doi.org/10.1016/S10811206(10)60491-7.

20. Cabana MD, Bradley J, Meurer JR, Holle D, Santiago C, Clark NM. Coding for asthma patient education in the primary care setting. J Med Prac Manage 2005;21:115-19.

21. Bower $P$, Wilson $S$, Mathers $N$. How often do UK primary care trials face recruitment delays? Fam Pract 2007;24(6):601-03. http://dx.doi.org/10.1093/fampra/cmm051

22. Lara M, Cabana MD, Houle CR, et al. Improving quality of care and promoting health care system change: the role of community-based coalitions. Health Promot Pract 2006;7(2 Suppl):87-95S. http://dx.doi.org/10.1177/1524839906287064
23. Kessler R, Glasgow RE. A proposal to speed translation of healthcare research into practice: dramatic change is needed. Am J Prev Med 2011;40(6):637-44. http://dx.doi.org/10.1016/j.amepre.2011.02.023

24. Glasgow RE. What types of evidence are most needed to advance behavioral medicine? Ann Behav Med 2008:35(1):19-25. http://dx.doi.org/10.1007/s12160007-9008-5

25. Ohadike YU, Malveaux FJ, Lesch JK. Challenges and lessons learned from the translation of evidence-based childhood asthma interventions: a commentary on the MCAN initiative. Health Promot Pract 2011;12(6):91-9S. http://dx.doi.org/ 10.1177/1524839911414565

26. Wilson KM, Brady TJ, Lesesne C. An organizing framework for translation in public health: the Knowledge to Action Framework. Prev Chronic Dis 2011;8(2):A46.

27. Westfall JM, Mold J, Fagnan L. Practice-based research: "Blue Highways" on the NIH roadmap. JAMA 2007;297(4):403-06. http://dx.doi.org/10.1001/jama.297.4.403

28. Education for Health. 2012. Available from: http://www.nrtc-usa.org/contact.htm (cited 25 Sep 2012).

Available online at http://www.thepcrj.org 